\title{
Cultural Differences in EFL Teaching Methods between Korean and Non-Korean Teachers
}

\author{
Thomas S. Jeffery ${ }^{1}$ \\ ${ }^{1}$ Youngshin Elementary School, Daegu, South Korea \\ Correspondence: Thomas Jeffery, Apartment 201, Daedong-ro 54-1, Buk-gu, Daegu, South Korea, 41563.
}

Received: November 14, 2021

Accepted: December 14, $2021 \quad$ Online Published: December 16, 2021

doi: $10.5539 /$ elt.v15n1p53

URL: https://doi.org/10.5539/elt.v15n1p53

\begin{abstract}
This study investigates key cultural differences in teaching between Korean and "western" teachers, and analyses these via questionnaires given to 35 Korean teachers and 36 non-Korean teachers followed by selected interviews. A significant finding was the emphasis Korean teachers place on testing compared to the "Western" teachers. The relevant literature explains this through Korea's socio-cultural Confucian context. This study also shows that verbal immediacy, power-distance, uncertainty avoidance and face saving are key elements in Korea's educational culture compared with western approaches to education.

Finally, qualitative data shows a strong preference by Korean teachers to move away from more traditional aspects of the classroom environment toward an approach where creative and critical thinking can be enabled.
\end{abstract}

Keywords: ESL, Korea, educational culture, pedagogical differences, teachers, Confucian

\section{Introduction}

This study aims to identify whether such a thing as a "Korean way" of teaching exists, and what Korean learning / teaching culture might encompass compared to classrooms taught by non-Koreans in Korea.

Through identifying teachers' educational philosophies it may be possible to reveal differences in teaching approaches between cultures. If differences exist, then one can ask what implications these may have for foreign language education, which is often taught from a "western" perspective with little regard for cultural backgrounds (Durkin, 2008). As Nguyen et al. summarize regarding western pedagogies in Confucian Heritage Cultures (CHC);

"Educational theories and practices from elsewhere, (the west) have been imported and applied without proper consideration for the host culture's heritage." (Nguyen, Terlouw, \& Pilot, 2006)

To establish key cultural differences variance between educational views are determined by a questionnaire, followed by interviews with select participants. If distinct variants occur and are shown to be culturally rather than individually based, Korean classrooms could be adapted, enabling more effective teaching by non-Korean teachers. As Butler suggests "contextually embedded adaptions" could be considered (2011).

Throughout, generalized stereotypical terms including "Confucian", "east" and "west" will be used. This is for simplicity rather than terminological accuracy and some of these terms will be challenged as being too simplistic (Clarke \& Xu, 2008). However, it is still possible to identify degrees of commonality across Confucian Heritage Cultures (CHC), and where appropriate, this will be addressed.

\section{Background}

\subsection{Educational Context}

Korea has a high proportion of students entering university, with great emphasis on the importance of "entrance exams". Over recent decades the Korean government has sought to match global economic ambitions with educational policies preparing citizens for international business. Throughout the early 1990s the government recognised that although students' English test scores were impressive, their communicative ability was lacking due to over reliance on a grammatical approach (Development Committee, 1992; Butler, 2011). This resulted in shifts toward communicative English and practical language uses such as Communicative Language Teaching (CLT) that concentrated on interaction (Hedge, 2000). 
However, there remains the cultural platform of a 600 years-old Confucian educational system (Lee \& Kim, 2017) and cultural pedagogical differences become apparent when western teachers come to Korea and teach from an anglocentric viewpoint. The CLT premise, a student and process-centred approach taught throughout many Korean English classrooms (Hedge, 2000; Butler, 2011), conflicts with core Confucian values (Durkin, 2008). As Simpson summerises;

"CLT, is bound up in and founded upon western ideals of "autonomy and egalitarianism, self-reliance and individualism" ( $\mathrm{Li}, 1998)$ which strikes discordantly with many Asian cultural norms for teacher-student relationships." (2008)

These differences between "eastern" and "western" teaching cultures are exacerbated by misalignments between goals set by Korean education policies for teaching more communicatively based English, and grammatically based examinations. The National University Entrance Examinations (similar to exams administered to pre-university high school students) do not reflect communicative testing. Instead, they are based on traditional education values with grammar-centred approaches, text-centred materials and teacher-centred methods $(\mathrm{Li}$, 1998). Although the National University Entrance Examination added listening comprehension in 1994, the majority remains grammar based. This partially explains Yan's (2020) identification of the importance second year university students attributed to grammar.

\subsection{Attitudes and Beliefs}

Another area of pedagogical conflict arises from classroom participation. Although this has changed as globalization erodes some traditional Confucian values, (Tudor, 2013) participation is not naturally a feature of Confucian countries' pedagogy as in western educational cultures (Li, 1998). "Face-saving", the act of avoiding embarrassment of correction is part of a broader Confucian approach of avoiding interrupting the learning process in a manner that could be perceived negatively (Simpson, 2008). In extremes, academics like Durkin state that Asian students in some $\mathrm{CHC}$ contexts avoid expressing personal opinions to avoid humiliation (Durkin, 2008). This could undermine aspects of western teaching requiring personal input, such as debate. Hence, imposing a western pedagogy with no adaption or consideration of its context may be inappropriate.

As a result of "face-saving", a more teacher-centred approach exists in Korean classrooms compared to western classes. Teacher dominated classroom control is referred to as "power-distance" and is more common in CHC classrooms (Park, Lee, \& Kim, 2009). Korea has scored highly when measuring such "power-distances" between teachers and students (Hofstede, 2001). In traditional Confucian environments teachers lead and along with books are perceived to be responsible for transmitting knowledge (Park et al., 2009). Hence, interrupting this knowledge transferal might be viewed negatively. In Heo et al.'s study of Finnish and Korean classrooms, Finnish students in Korea were quick to identify the authority of the Korean teacher and the less freedom students felt questioning teachers (Heo, Leppisaari, \& Lee, 2017).

\subsection{Complications}

Cultural differences might also exist within subjects. In science, knowledge transfer from teacher to student might be implicitly accepted because the subject is factually based. This may help explain the deference to authority in Lee and Kim's study of Korean science teachers (Lee \& Kim, 2017). Hence, subjects, contexts, teachers and students may dictate classroom culture as much as the wider cultural background. There could be unique subject specific sub-cultures, which is supported by Mitchell and Lee's study of Korean communicative teaching. This found that Korean English classrooms demonstrated far greater group / co-operative learning because of the subject rather than any cultural reflection (Mitchell \& Lee, 2003). Osborn et al. argued that while classroom culture reflects the broader society (Osborn, Broadfoor, McNess, Planel, Raven, \& Triggs, 2003) this can be oversimplified. Cheng argues some classroom factors are "situation specific rather than culturally pre-set" (2000). Garner's study also supports this concept. He states, "every class has its own culture" (1989), potentially obscuring preset cultural values. Both are important points that complicate attempts to identify a "Korean way" of teaching.

Finally, referring to teachers and methods, Heo et al.'s study of Korean teachers compared to Finnish counterparts found Korean teachers to be more textbook oriented, emphasising theoretical approaches. Again, this may result from links to traditional learning values and the importance of textbooks as key to accumulating knowledge (Ting, 2008; Heo et al., 2018), this may help to explain the rote learning still found in many Korean schools (Dong, Anderson, Kim, \& Li, 2008). 


\section{Literature Review and Question Design}

The questions used in the questionnaire were based on related research focusing on issues teaching communicative approaches to language teaching in Asia. The second set of questions used were for in-depth interviews with six individuals. As this second set of questions were based on data arising from the questionnaire, they are briefly discussed.

\subsection{Recitation and Memorisation}

The focus placed on recitation and memorisation as significant subjects came from Dong et al.'s study of Collaborative Reasoning in China and Korea (Dong et al., 2008). Its relevance was that its classroom observations were undertaken in the same city as this study; Daegu and picked up on a theme raised here; the importance placed of memorisation and recitation. As Dong et al. state; "Memorization is still the main feature of both Chinese and Korean education" (2008). Therefore there was a need to include a statement to see if differences exist between the two teaching groups (Korean and non-Korean) in this study. The statement created was;

"Memorization is the best way to get students to remember important information."

\subsection{The All-Knowing Teacher}

Dong et al.'s study also revealed the emphasis on teachers as vehicles for knowledge attainment, as summarized by; "The students seemed to regard their teacher as a know-all authority" (2008). Park et al. (2009), noted a similar trait observing power distance as a reoccurring theme in traditional $\mathrm{CHC}$ education. Such a sentiment was argued by Butler more forcefully;

"The teacher was seen (in Asia) as the possessor and messenger of profound knowledge, and the student as the recipient of that authoritative knowledge". (2011)

However, both Butler and Dong et al. pointed out that the climate regarding CHC pedagogies was rapidly changing, due to globalization (Dong et al., 2008; Butler, 2011). An aim of this study was to see if such a theme was present many years after these studies. The question posed was;

"It is my role as the teacher to give knowledge to my students".

\subsection{Tests}

Imbalances between examinations and the goals of the Development Committees' government published paper (Development Committee, 1992) has already been mentioned, and the importance placed on examinations has been explained. However, whether differences in positions on exams between Korean and non-Korean teachers were present remained unknown and could be a significant area of disagreement. The two statements created were;

"Without tests we cannot truly understand a student's ability."

"A smart student should score well on tests."

\subsection{Face-Saving, Power-Distance and Uncertainty-Avoidance}

Considering the topics discussed, it may be assumed that Korean teachers would be more adverse to students correcting their mistakes. The loss of face could be more extreme for a Korean than "western" teacher who may experience some embarrassment, but not hold such strong Confucian socio-cultural values regarding face-saving and power-distance. A third concept that may also influence classrooms in CHC countries is uncertainty-avoidance, a discomfort with unpredictability (Nguyen et al., 2006). Hofstede and Hofstede statistically categorized $\mathrm{CHC}$ nations along the five dimensions considered to be obstacles to western pedagogies applied in Confucian contexts (Hofstede \& Hofstede, 2005). Uncertainty-avoidance was one they identified. Out of the seven CHC nations measured, Korea was ranked second in this respect (Hofstede \& Hofstede, 2005). Thus, three statements were created. The first two focused on saving student embarrassment and the final statement was based on teacher comfort level when presented with a publicly embarrassing situation. They were;

"When a student makes a mistake, it is best to correct the mistake straight away."

"Sometimes I ignore errors completely as I feel it will disrupt the student's learning or confidence."

"I dislike it when I have made a mistake and a student corrects or questions me."

This final statement emanated from Nguyen et al.'s study of CHC contexts that examines what happens when teachers make mistakes or errors in strong power-distance cultures. When faced with teacher error, the 
importance of face-saving could determine how teachers respond to challenges. Hence, Nguyen et al. described what occurred in a Vietnamese classroom after a teacher was corrected in front of the class;

"Instead of accepting that this was a mistake, the teacher felt offended and said: 'If you think you know more than me, come up here and replace me as the teacher!' (Personal Communication, 2002)" (Nguyen et al., 2006).

Returning to Hofstede and Hofstede's study, when considering power-distance, it is noted that Vietnam ranks above Korea in their index of $\mathrm{CHC}$ measured nations regarding power distance, however, not significantly so (Hofstede \& Hofstede, 2005). Hence, the need to gauge teachers' responses.

\subsection{Teacher Control}

Another recurring theme was classroom control, the degree to which teachers identified as classroom leaders, and how willing they were to cede control. The concept for this question came from Park et al.'s study of teacher authority in the US and Korea (Park et al., 2009). This study pointed to differences in how teachers exercised authority within classrooms, a difference that may have resulted from the culture and context of classes and participants. It may be possible that differences could be shown in data between the Korean and non-Korean groups regarding teacher control. The statements created to address this topic were;

"I will let my students have a say in what we study and how long we study it for."

"I am the leader of my class."

\subsection{Verbal Immediacy}

Park et al. also discussed verbal immediacy; the degree to which a message is explicitly communicated or if it can be transmitted contextually (Park et al., 2009). It differs by country and Korea is a high-context nation according to Gudykunst and Nishidas' study (1986). Hence, Korean society relies significantly on context to transmit messages, whereas western nations demonstrate the opposite (Park et al., 2009). Presumably, in a low-context culture teachers would explicitly state important information. In a high-context culture they might not feel such a need, as students would pick up on social cues. Durkin states, “....in these high context cultures, inference rather than explicitness is preferred" (2008). However, Gudykunst and Nishihas' study is 35 years old (1986), and considering globalization, this is a significant period of time for ESL Korean teaching. As such, the statements designed were;

"Instructions should be explicitly stated rather than have students figure things out."

"Clearly explained classroom rules are important to ensuring class harmony."

\subsection{Seating Plans and Class Rules}

Shin and Koh's study examined teachers' views on classroom management in Korean and American schools (2007). This study showed notable differences, stating; "(there were) significant cross cultural differences in beliefs of American and Korean teachers" (2007). The most prominent fell into two categories; seatwork / seating plans and class planning. American teachers favoured seating plans more than Koreans with $51 \%$ of Americans wanting assigned seats compared to $26 \%$ of Koreans. This difference felt important enough to include as a questionnaire topic. The statement designed to test this was;

"Seating plans are important to create a good learning environment."

The second significant statistical difference that Shin and Koh's uncovered was with reference to lesson planning. This difference was more extreme with $78 \%$ of American teachers preferring to stay within designated lesson plans compared to $23 \%$ of Koreans (Shin \& Koh, 2007).

As such the following statement was designed;

"I have a plan for my class and I feel uncomfortable if I do not follow that plan."

\subsection{Collectivism or Individualism}

The inclination towards unity or the group within "eastern" cultures and the individualistic tendencies within "western" cultures is well documented. Nguyen et al. argues, "Group learning is assumed to be culturally appropriate in CHC and many Asian collectivist nations" (2006). As a result of globalization, it is questionable if describing Korea as a collectivist society is still an accurate national representation. However, "individualism" and "collectivism" are not necessarily opposites. Some studies such as Park's (2002) show Korean students' negative responses to group learning, as group activities could undermine individual achievement because of weaker members (Nguyen et al., 2006). Hence, anti-individualist tendencies do not mean support for notions of 
educational collectivism. While simply arguing that Koreans show strong collectivist tendencies and non-Korean participants are individualistic is oversimplifying, the literature does support the concept that culture influences ideas along the collectivism/individualism dimension. Hence, the following three statements were created to explore such patterns;

"Class harmony is more important than individual happiness."

"When doing group work, having one student in a group who leads the group is helpful even if he / she dominates the group."

"Group work is important as it can make shyer students feel included."

\subsection{Open-Ended Question and Individual In-Depth Interview Questions}

Finally, an optional open-ended question was created at the end of the questionnaire, giving each group of participants the opportunity to expand on concepts. It was as follows;

"This final question is completely optional. If you do not want to complete it please just type in "NO". Are there any differences in teaching / learning that you have noticed when observing foreign or Korean teachers comparing Korean teaching to other countries?"

For the qualitative study, individual interview questions were based on data from questionnaire answers offering opportunities to provide detail where the two groups differed significantly. The five topics of significant cultural difference were; tests, memorization techniques, individual / group concepts, lesson plans and use of explicit rules. For the full list of interview questions, please refer to the appendix.

\section{Methodology}

\subsection{Purpose}

Data collection had a two-part approach; a questionnaire / survey to find if differences existed between 35 Korean and 36 non-Korean teachers' views, undertaken with participants from several subject disciplines, followed by an interview with select English language teachers to gain an in-depth understanding of key areas of variance. Therefore, all data came from primary sources.

\subsection{Tools and Data Collection}

Two survey variations were created through the data and survey creation programme Qualtrics, one for Korean teachers and one for non-Koreans to ensure no data cross contamination. Survey questions were translated into Korean so that participants answered identical questions. The in-depth interview questions were based on data that showed high group variance.

\subsection{Participants}

The 71 participants used in the questionnaire and six interviees were female, controlling for gender. For the interviews, two candidates were American (for the "non-Korean" category). The two Korean candidates were chosen based on location. The final two candidates posed a problem for data classification but because of their background provided an ability to give rich qualitative data that blurred the "Korean" - "non-Korean" cultural differences. One American born with a Korean parent having lived in both countries. The other Korean born with significant periods spent living in the UK. Hence, neither were easily categorized.

One stated;

"I'd describe myself as... Korean. But if we're talking about Korean Korean here, probably I wouldn't fall under that category if that makes any sense at all. I can fit in this kind of culture, but at the same time I don't fit in." ("Mixed" Interview Candidate 2)

The other interview candidate similarly described her position as,

“(I'm)... a mix. I don’t identify fully with either culture." ("Mixed” Interview Candidate 1)

Data arising from both candidates was assigned to the non-Korean category as this felt most appropriate considering their background and pedagogical outlook.

\subsection{Data Analysis}

Results from the 16 questionnaire statements showed six areas revealing group variance. These were identified mostly through outliers represented by a group not selecting a likert scale option. Hence, if out of the 35 Korean participants none selected "strongly agree" to an answer it was viewed as a topic of interest. Where this did not apply was if the other group, (non-Korean) showed similar data as this presumably represents a teaching method 
or viewpoint that was not popular rather than a cultural difference. The qualitative data was analysed thematically with key words such as "tests" searched for through the five categories identified by the questionnaire.

\subsection{Methodological Reasoning}

The questionnaire and interview were designed to work together to extract the most data. The questionnaire would gain a quantitative understanding of key areas of variance. Subsequently, the interviews would explore qualitative aspects. Questionnaires had been used in similar studies dealing with cultural challenges in anglocentric pedagogies in the Korean contexts ( $\mathrm{Li}, 1998)$. A five-point likert scale was used with degrees of responses from "strongly disagree" to "strongly agree". Thus, the two methods together fit the research topic and helped to balance each other's weaknesses.

\section{Data, Analysis and Limitations}

\subsection{Closed Questionnaire Data}

There were six questionnaire answers on five different topics showing significant variance between data sets. Each time the results are represented, the non-Korean group is displayed in red, followed by the Korean group in blue. On each the number of participants who selected an option is shown below.

\subsubsection{Tests}

Data on tests came from two statements. The first was; "Without tests we cannot truly understand a student's ability." The results were:

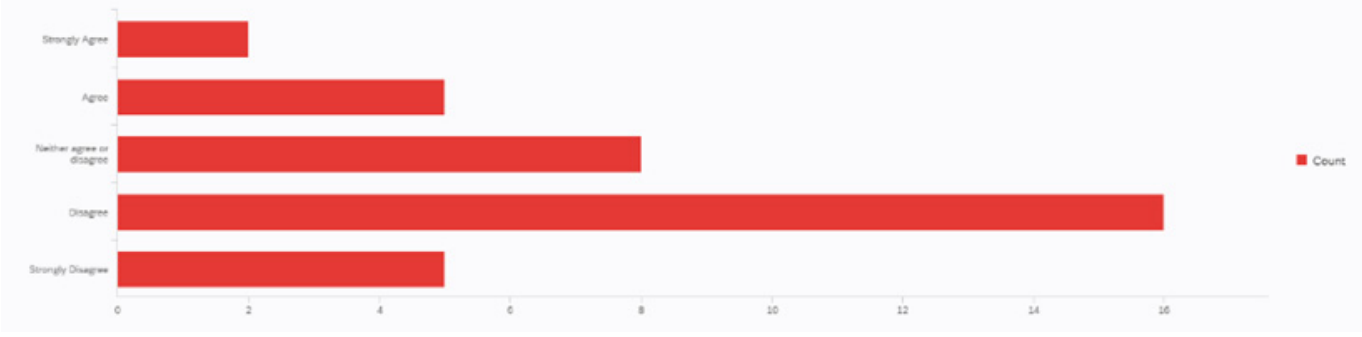

Figure 1a. Non-Korean Responders

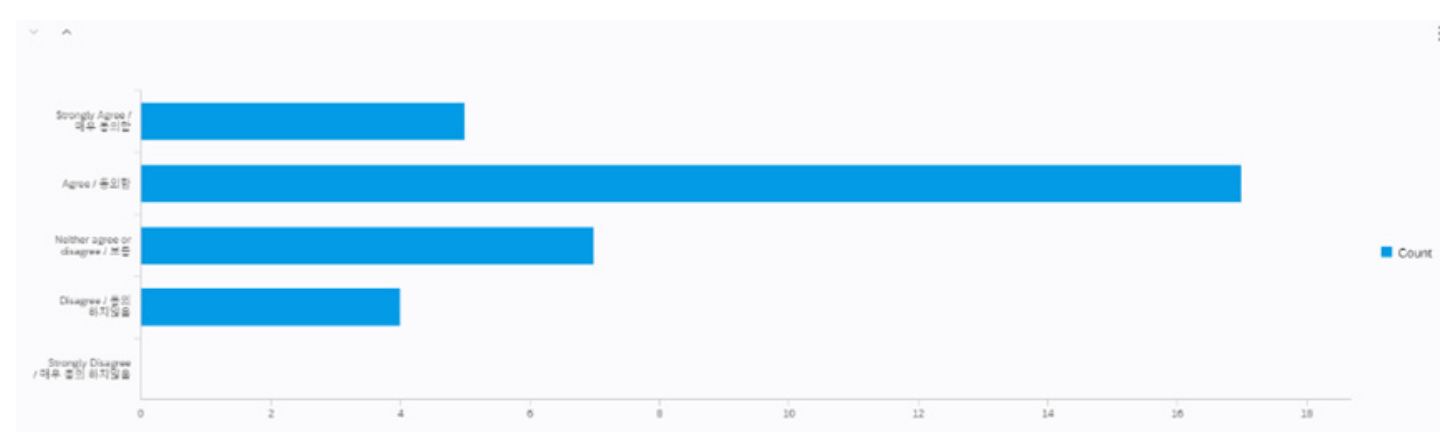

Figure 1b. Korean Responders

Figures $1 \mathrm{a}$ and $1 \mathrm{~b}$ Non-Korean and Korean responses to the following statement; "Without tests we cannot truly understand a student's ability."

$66 \%$ of Korean responders either agreed or strongly agreed with the statement and $58 \%$ of non-Korean responders disagreed or strongly disagreed. Out of the 35 Korean responders, none strongly disagreed. 
The second statement on tests was, "A smart student should always score well on tests." The results were:

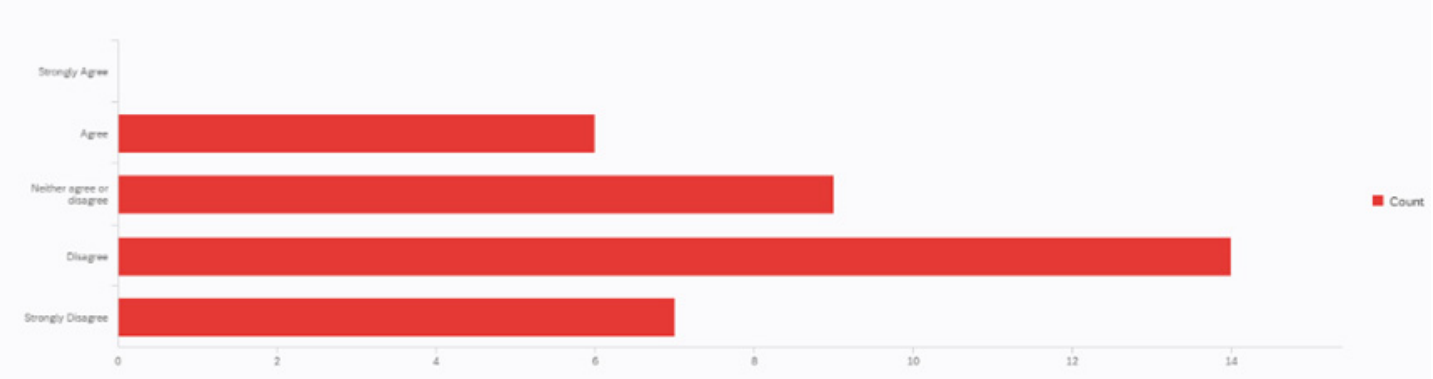

Figure 2a. Non-Korean Responders

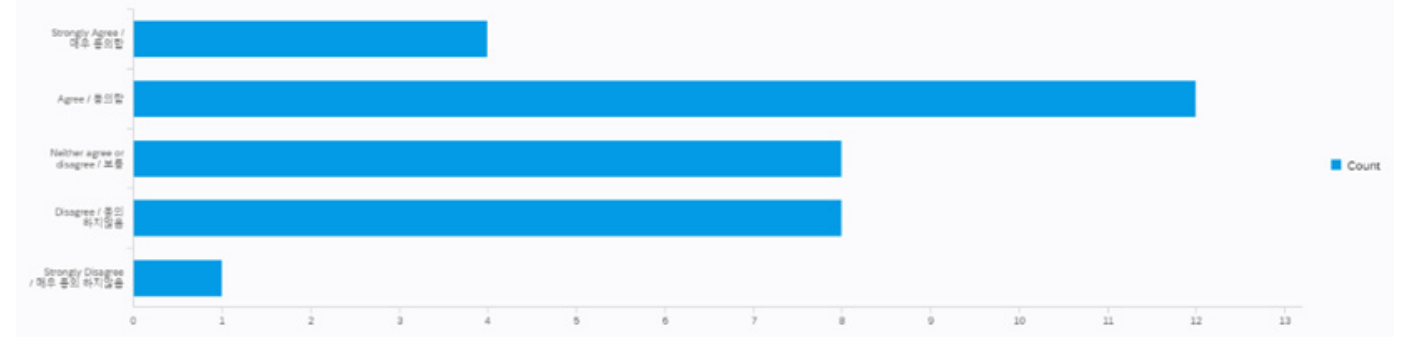

Figure 2b. Korean Responders

Figures $2 \mathrm{a}$ and $2 \mathrm{~b}$ Non-Korean and Korean responses to the following statement; "A smart student should always score well on tests."

The non-Koreans strongly disagreed with the statement. 58\% responded negatively. No responders from the non-Korean group "strongly agreed". The Korean group responded significantly more favourably, with only $27 \%$ of responders giving negative answers.

\subsubsection{Memorisation}

The next topic showing between group variance was the use of memorisation class techniques. The statement was; "Memorisation is the best way to get students to remember important information". The results were:

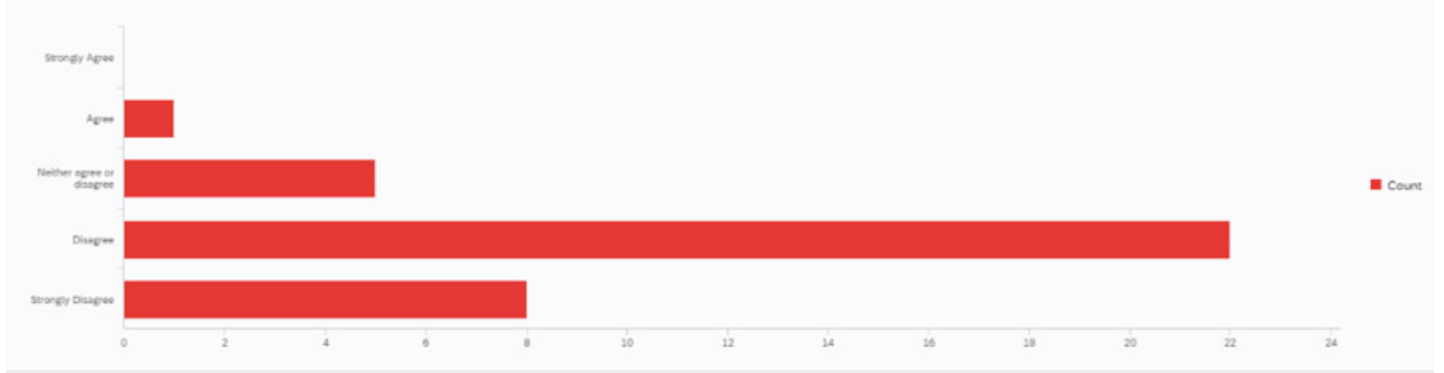

Figure 3a. Non-Korean Responders 


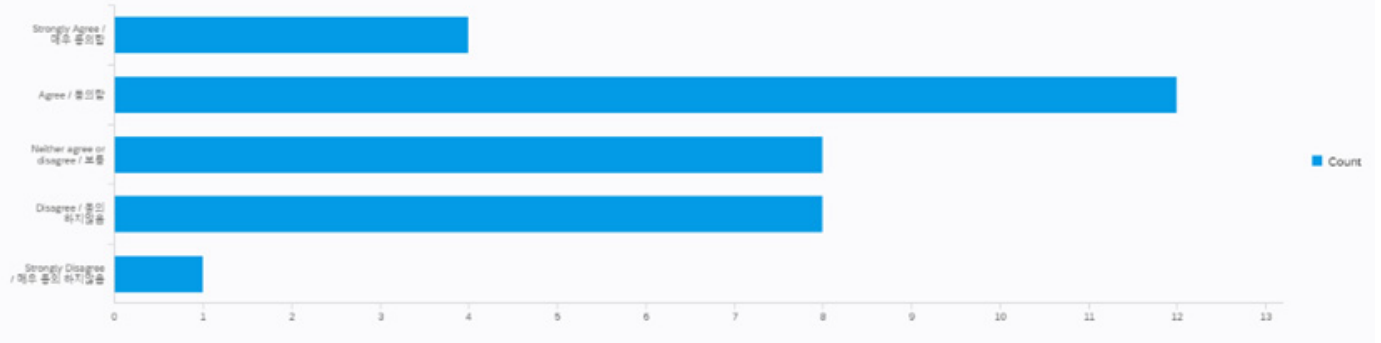

Figure 3b. Korean responses

Figures $3 \mathrm{a}$ and $3 \mathrm{~b}$ Non-Korean and Korean responses to the following statement; "Memorisation is the best way to get students to remember important information."

The Korean group showed only a slight tendency to prefer memorisation techniques overall, $(27 \%$ responded negatively and $30 \%$ positively) but non-Koreans showed a strong aversion to the same statement. None of the responders of the non-Korean group "strongly agreed" and $83 \%$ responded negatively.

\subsubsection{Individual or Group Orientation}

The statement designed to explore if there were differences in the way the two groups saw individualism as a result of their cultural backgrounds was; "Classroom harmony is more important than individual happiness." The results were:

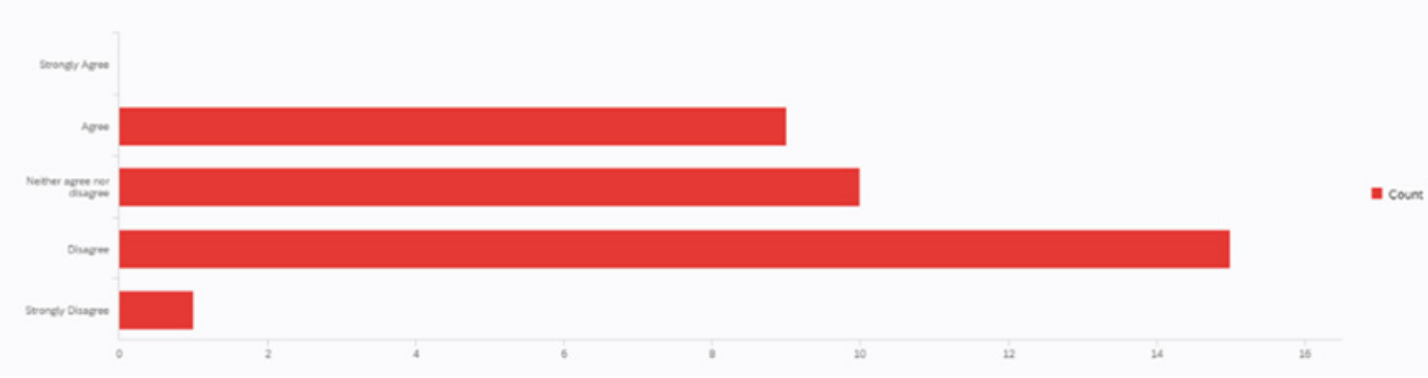

Figure 4a. Non-Korean Responders

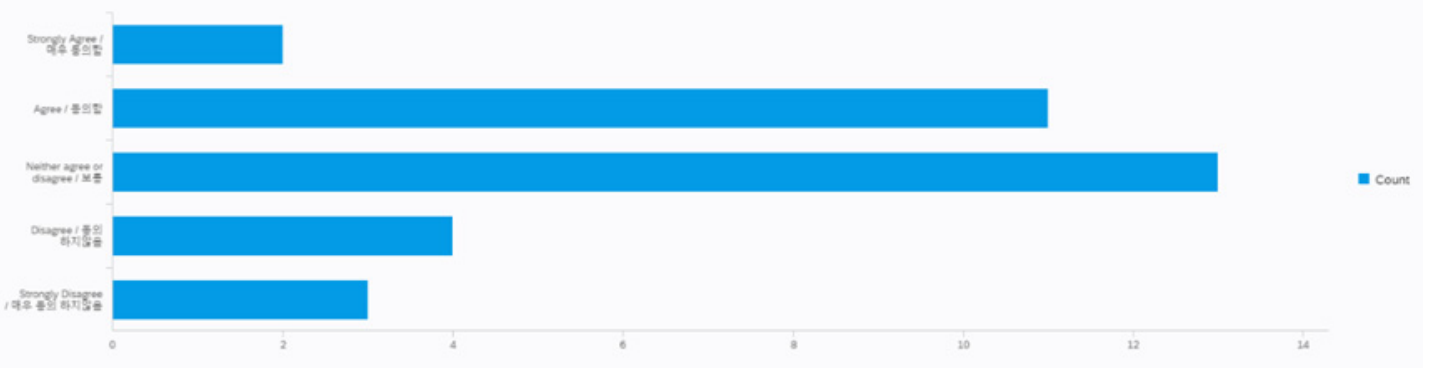

Figure 4b. Korean Responders

Figures $4 \mathrm{a}$ and $4 \mathrm{~b}$ Non-Korean and Korean responses to the following statement; "Classroom harmony is more important than individual happiness."

The results here were subtle. The non-Korean group showed an aversion to the idea of sacrificing individual happiness with no participant selecting "strongly agree". Nearly half of all non-Korean responders, (45\%) responded negatively. For the Korean group the number of negative responses was $21 \%$.

\subsubsection{Lesson Plans}

Lesson plans were identified as a possible area of difference. The statement created was "I have a plan for my class and feel uncomfortable if I do not follow that plan". The results were: 


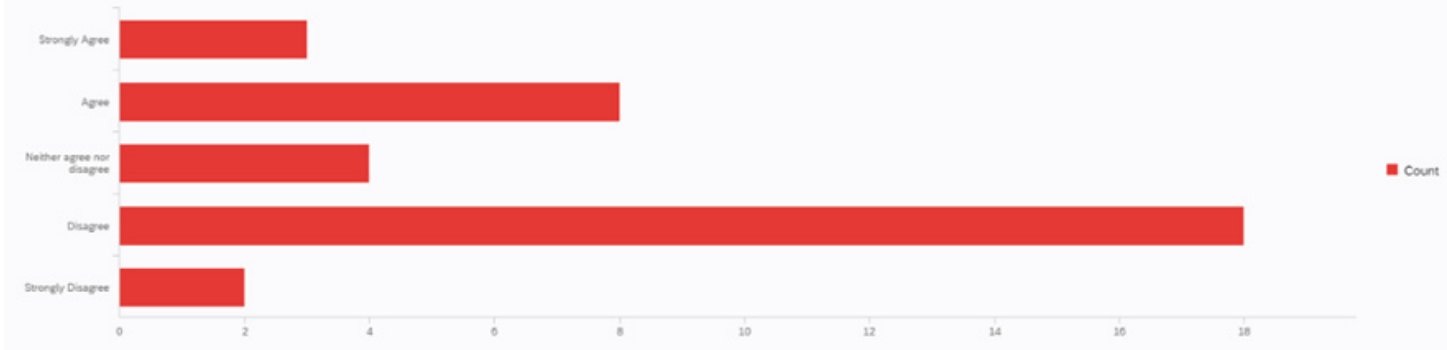

Figure 5a. Non-Korean Responders

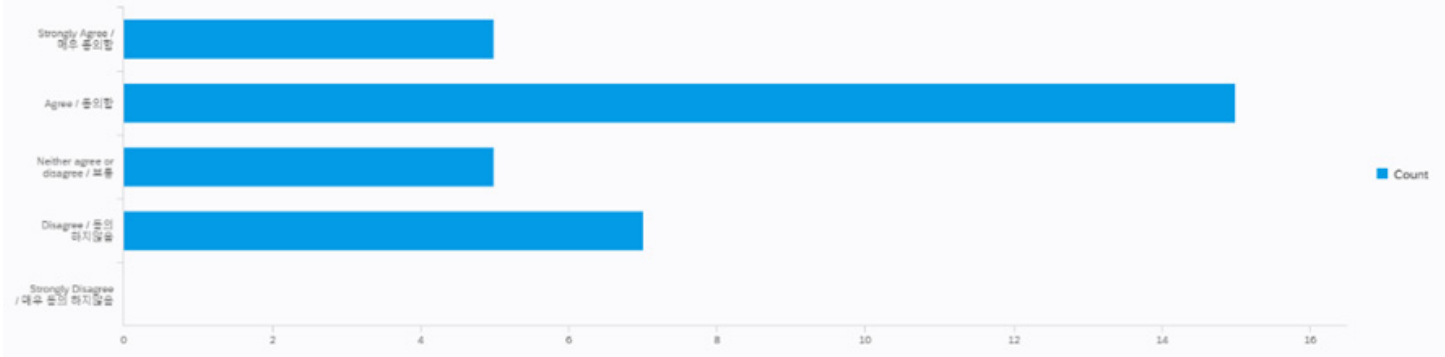

Figure 5b. Non-Korean Responders

Figures $5 \mathrm{a}$ and $5 \mathrm{~b}$ Non-Korean and Korean responses to the following statement; "I have a plan for my class and feel uncomfortable if I do not follow that plan."

Non-Korean data disagreed strongly with this with over half of participants indicating they feel comfortable improvising and operating in a classroom environment without a set structure. More than half of participants responded negatively (57\%). The Korean group showed a strong opposite inclination. $62 \%$ responded that they would feel uncomfortable not following a lesson plan. Furthermore, none of the Korean participants "Strongly Disagreed" with the statement.

\subsubsection{Implicit Instructions}

Attitudes towards rules and instructions arising from cultural background, (high context cultures and low context cultures) can dictate whether people feel the need to explicitly state instructions. A statement designed to test this was put to the two groups as follows: "Instructions should be explicitly stated rather than have students figure things out." The results were:

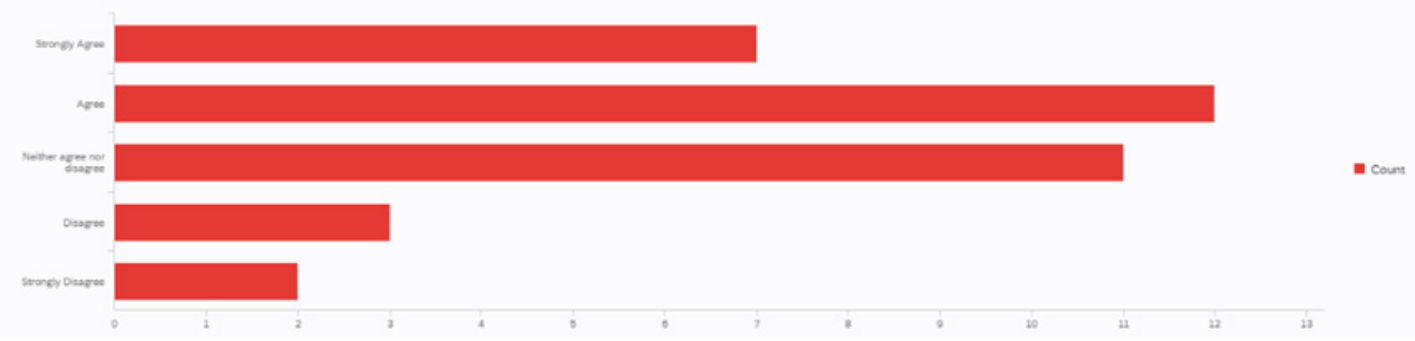

Figure 6a. Non-Korean Responders

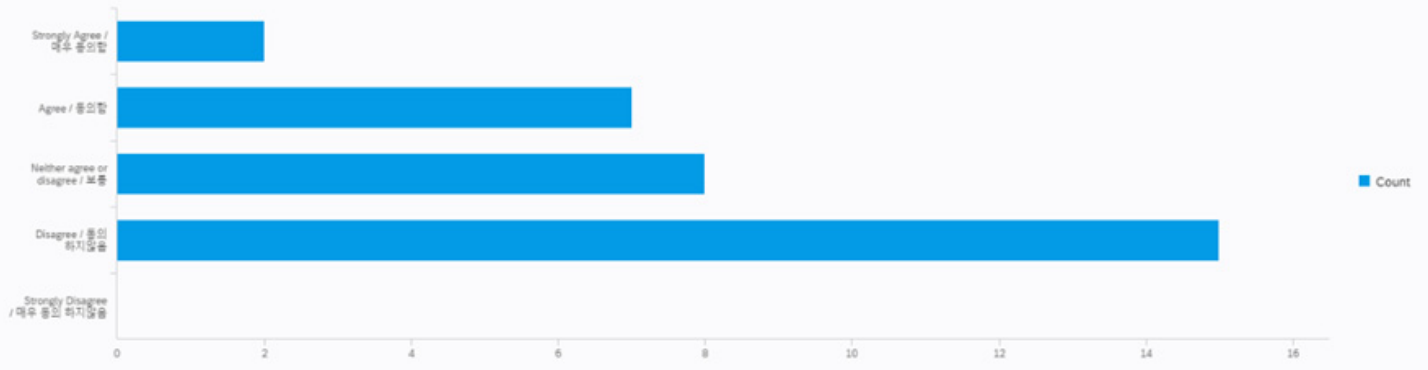

Figure 6b. Korean Responders 
Figures $6 \mathrm{a}$ and $6 \mathrm{~b}$ Non-Korean and Korean responses to the following statement; "Instructions should be explicitly stated rather than have students figure things out."

The non-Korean group favoured the use of explicit instructions with $54 \%$ showing a preference for their use. $46 \%$ of the Korean group disagreed compared to only $8 \%$ of the non-Korean group.

\subsection{Open-Ended Questionnaire Questions}

The open-ended question was designed to give participants opportunities to expand upon questionnaire themes or offer their own insight on the topic. When coded for themes the participants of the two data groups showed similar reoccurring themes; tests, memorization and critical thinking.

\subsubsection{Tests}

Tests were a consistent theme discussed amongst both groups with both commenting on Korean education focusing on examinations for cultural reasons. As one Korean participant stated:

"Korean teachers are highly exposed to Korean test customs. For that reason, it may be not possible for them to abandon the "Grammar Translation Method..." (Korean Teacher Response \#12)

\subsubsection{Memorisation}

Memorisation was mentioned nine times between the two groups. All the responses on the subject appeared to be negative:

"Memorizing is most valued. Quantity over quality..." (Non-Korean Teacher Open Ended Response \#15)

Several answers combined both memorization and tests. Such as:

“...Korean classes are only focused on memorizing answers of the exam..." (Korean Teacher Open Ended Response \#19)

\subsubsection{Critical Thinking}

The findings relating to critical thinking were unexpected. Both groups criticised the lack of critical thinking, saying it was not encouraged within the Korean educational environment. Non-Korean responders frequently linked this to a lack of creatively as shown below:

"The teaching style here is memorization, authoritative. There is not much if any critical thinking taught, "how" questions are extremely hard for Korean students to answer because they have to explain their reasoning and that is not taught." (Non-Korean Teacher Response \#3)

“...Students are not encouraged to think critically or creatively.” (Non-Korean Teacher Response \#15)

The Korean responses differed. Explicit use of the words "critical thinking" only occurred once. However, this may be a result of language differences. The first Korean response is key to understanding this:

“Overall, foreign teachers listen to and respect students' opinions, and in Korean education, expressing their opinions by students is often viewed as a challenge or rebellion against authority. The development of creative / critical thinking of children can be made only when an atmosphere in which students can speak again should be further formed in Korean education." (Korean Teacher Response \#7)

Expanding upon this, several other responses could also be included in spite of the fact that they lack any mention of the specific term "critical thinking". Although there are various definitions of it, most include analyzing and expressing a personal judgement (Hedge, 2000). This process requires an atmosphere valuing freedom to form opinions without fear of criticism. If so, then the following open-ended responses might be considered as prerequisites to critical thinking and linked to the subject:

"The Atmosphere that feels that free speech interferes with the class seems to be the Korean style." (Korean Teacher Response \#4)

"Debate and participatory class (is the) foreign class method." (Korean Teacher Response \#2)

"It (Korean education) should be changed to a student-led type, not an injection type by a teacher." (Korean Teacher Response \#1)

Whether these three responses are true representations of "critical thinking" is contentious. 


\subsection{In-Depth Individual Interview Data}

The interview data is broken down into the subsections participants were grouped into. These were Korean, "mixed" (half-Korean) and non-Korean. There were six interviews in total (two for each category). Data were analysed in terms of the subject discussed and the frequency with which topics arose.

\subsubsection{Korean Responders}

Both Korean interviewees considered tests to be important, either to separate students into levels or just for general feedback. However, one teacher questioned whether this was overemphasised in Korean culture, stating:

"Koreans are too focused on tests and separating students based on their level." (Korean Interviewee \#1)

Both teachers also showed a strong inclination toward explicitly explaining class rules to students. When asked about the need for explicit rules one responded:

"Rules are absolutely necessary, I always try to tell my students about my classroom rules." (Korean Interviewee \#1)

\subsection{2 "Mixed" Responders}

Both "mixed" responders' appeared to reject more traditional aspects of Korean education. Their responses were notable for their dislike of Korean testing culture and memorisation methods. When considering differences between the Korean approach and more western styles, one interviewee stated:

"Koreans are really into finding the result. Whereas all the other people, (western?) are into the process. Koreans are always asking "what's your score?"... (“Mixed" Interview Candidate \#2)

The dislike of conventional tests and memorisation was summarised by the same interviewee who stated:

"I am very against traditional, conventional tests. The questions we should ask is about the whole story, not just details (in reference to Korean testing which is based more on memorisation). A lot of Koreans are supposed to remember tiny little details about everything." ("Mixed" Interview Candidate \#2)

The other "Mixed" candidate echoed similar sentiments. She viewed tests and memorisation as archaic and pointed to the notion of subject change over time;

"I have seen a very big change in that style. It used to be complete memorization. What kids were doing was memorising for a test or a specific situation. I don't find memorization in the classic sense to be useful at all." ("Mixed" Interview Candidate \#1)

\subsubsection{Non-Korean Responders}

In line with the quantitative data both non-Korean participants interviewed tended to avoid lesson plans. They showed further alignment with non-Korean teachers, viewing tests in a more negative manner than their Korean counterparts. This can be summarised by the following two quotes:

"We shouldn't be relying so much on them (tests)." (Non-Korean Interviewee \#1)

"I don't think they're a good representation of a person's skills." (Non-Korean Interviewee \#2)

\subsection{Analysis and Discussion}

The most salient differences between Korean and non-Korean teachers data were: tests, lesson plans, implicit instructions and critical thinking.

\subsubsection{Tests}

The most significant finding related to different teachers' views on tests. Data on the questionnaire in section 5.1.1 supports the notion that Korean teachers valued tests to gauge students' ability more than non-Korean teachers. This was unsurprising considering the importance of tests within the Korean educational system. Specifically, the Korean group appeared to prefer using tests to group students according to ability compared to non-Koreans (5.1.1, 5.2.1, 5.3.1 and 5.3.3). Data supports the idea that tests in Korea are valued by Korean teachers as an intrinsic part of the education unlike non-Korean participants.

\subsubsection{Lesson Plans}

Data presented in section 5.1.4 demonstrated that the Korean participants showed significantly more bias toward lesson planning than the non-Koreans. However, as this was not supported by findings in the open-ended questions or strong statements in the interviews, it is not possible to come to firm conclusions about this being a culturally related phenomenon. 


\subsubsection{Implicit Instructions and Verbal Immediacy}

Data from 5.1.5 supported the research from section 3.6 that explicitly stated directions were not as significant for Korean teachers compared with their "western" counterparts. When referring back to Park et al. (2009) and Gudykunst and Nishida (1986), this could be because Korea is a high-context culture that relies less on verbal immediacy (explicitly stating messages). However, qualitative data from the two Korean teachers in section 5.3.1 does not support this as interviewees showed an inclination toward explicitly stated rules regardless of cultural background. As qualitative data collected on the issue ran counter to questionnaire findings, (5.3.1) further studies are needed to seek resolution.

\subsubsection{Student-Centred Classroom Environment and Creative or Critical Thinking}

The sheer quantity of Korean responses to the open ended question that alluded to the notion of critical thinking is noteworthy (5.2.3). "Critical thinking" as a term does not seem to be specifically recognised by Korean teachers (at least in this study), but instead is implied. The issue is how to recognise whether a teacher is implying the need for critical thinking without explicitly stating it. Presumably, it would be defined as the need for a student-centred environment that favoured process based learning as opposed to a product based approach? If so, the following responses could be considered as being intrinsically linked:

"It should be changed to a student-led type, not an injection type by the teacher." (Korean Teacher Response \#1)

"Debate and participatory class (is) foreign class method." (Korean Teacher Response \#2)

"...Some teachers focus on giving a lecture rather than teach... I think interaction should be involved." (Korean Teacher Response \#20)

Power-distance, face-saving, uncertainty-avoidance and teacher-centred environments appear to be what the responders were referencing above. Students feeling unable to engage openly with teachers could be a pre-requisite to enable critical thinking. Therefore, the following responses could be considered relevant:

"The atmosphere that feels that free speech interferes with the class seems to be the Korean Style." (Korean Teacher Response \#4)

"In America, the teachers always try to ask various questions about the topic to the students. Even though the (student) answers are not related to the topic closely, teachers tend to respect them." (Korean Teacher Response \#13)

All these responses link back to the literature and are associated with the creation of a student-centred environment that could enable critical thinking and a freer classroom discourse. However, without quantitative data based on a specific question and the language barrier with regards to the term "critical thinking", confident statements from data are hard to conclude. The study's qualitative data does seem to support the view that many Korean teachers see a need for freer more open classroom environments. As the following statement from the non-Korean participants below demonstrates;

"...There is a limitation on creative thinking because of the style of teaching. Students are not independent thinkers, they believe in only one answer." (Non-Korean Teacher Open Ended Response \#3)

"Students have no critical thinking (and) are not taught inquiry based learning whatsoever." (Non-Korean Teacher Response \#7)

\section{Limitations, Conclusion and Recommendations}

\subsection{Limitations}

\subsubsection{Selected Participants}

Participants were not randomly selected. Finding Korean female teachers was difficult and most came from Daegu which is the heartland of the Saenuri party who espouse a conservative social and national policy (Tudor, 2013). As the majority of the Korean participants were native to Daegu, the Korean data may have conservative leanings on topics such as classroom management and discipline. The second issue was that two candidates did not clearly fit into categories. They were categorized as "mixed" but both were born in Korea with Korean citizenship. However, their results only equate to $5 \%$ of the total non-Korean questionnaire data. 


\subsubsection{Translations}

Some of the Korean participants who answered the interview questions (in English), may not have been able to fully convey their opinions as they used their second language which could have reduced nuance and distorted what they meant to say.

\subsubsection{Critical Thinking}

A further consideration is if a question could have been included on critical thinking. This became apparent when assessing the open-ended responses to the survey questionnaire data. At this point, individual interviews where a question could have been included were already underway.

\subsubsection{Data Limitations}

Qualtrics was used for the questionnaire, which could not link answers to individuals, meaning controlling for age was impossible. Teaching English in Korea is changing rapidly. Views and studies from a decade ago may no longer be relevant. Consequently, age or experience may have affected answers significantly. This issue was raised by the half-Korean half-American interviewee who claimed that younger teachers saw their teaching practices in a very different way to older teachers. She stated;

"I have taught for over a decade here... the teaching style has changed a lot. It seems a lot more of the younger generation teachers are doing away with pure memorisation based studying. Small differences such as allowing left-handedness in the class, when even a few years ago this was frowned upon." (Open ended Response \#5)

\subsubsection{Likert Scale}

Finally, I adopted a five point likert scale leaving room for a neutral option. Throughout Shin and Koh's study on differences between South Korean and American teachers' views on educational issues, one choice they made was to use a 4 point likert scale as opposed to a five point scale, removing a neutral option (2007). However, they still found that Korean participants avoided the more extreme stances compared to their American counterparts. As they state;

"The Korean participants were inclined to avoid the extreme alternatives, (on the questionnaire)... and choose more moderate and safe options instead." (2007).

I observed a similar pattern in data from Korean participants. Foreign teachers selected the neutral option on the scale 98 times while Korean participants selected it 133 times. Therefore, it is possible that Koreans were more moderate in their views compared to non-Koreans as a result of culturally influenced factors.

\subsection{Conclusion and Recommendations}

Data indicates pedagogic differences between Korean and Non-Korean participants. Firstly, it substantiates that the two groups place a different emphasis on tests (5.1.1). Secondly, it shows a Korean preference for lesson planning (5.1.4) compared to non-Koreans. It also suggests Korean teachers use fewer explicit rules and instructions (5.1.5). An explanation resides in the cultural context: Korea shows a high degree of Confucian heritage (3.6). However, qualitative data from the individual interviews did not always support this, perhaps due to small sample size. Significantly, this study reveals a desire on the part of Korean teachers to move on from traditional aspects of Confucian led education towards a more "western" model. This would encompass a more student-centred classroom environment with more encouragement of critical thinking and creativity (5.4.5 and 5.3.3), and a more process-based approach to learning.

The results of this survey indicate an interest in moving towards a more student led classroom. In addition, as outlined in section 2.1, the government has placed priority on practical communication within language teaching, implying, perhaps, a move to a more "western" model of classroom practice. However, despite these developments, non-Korean teachers need to be aware that Korean cultural heritage places strong and continuing emphasis on grammar and testing, and that this is not likely to change significantly in the foreseeable future.

\section{References}

Butler, Y. (2011). The Implementation of Communicative and Task Based Language Teaching in the Asia-Pacific Region. Annual Review of Applied Linguistics, 31, 36-57. https://doi.org/10.1017/S0267190511000122

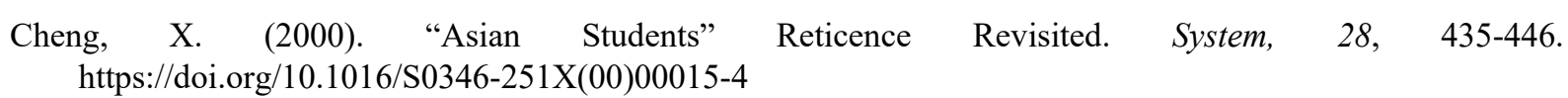


Clarke, D., \& Xu, L. (2008). Distinguishing Between Mathematics Classrooms in Australia, China, Japan, Korea and the USA Through the Lens of the Distribution of Responsibility for Knowledge Generation. ZDM Mathematics Education, 40, 963-972. https://doi.org/10.1007/s11858-008-0129-5

Development Committee of the Sixth Curriculum for High School English. (1992). The Report on the Revision of the English Curriculum for High School Seoul. Korea.

Dong, T., Anderson, R., Kim, I., \& Li, Y. (2008). Collaborative Reasoning in China and Korea. Reading Research Quarterly, 43(3), 400-324. https://doi.org/10.1598/RRQ.43.4.5

Durkin, K. (2008). The Adaption of East Asian Masters Students to Western Norms of Critical Thinking and Argumentation in the UK. Intercultural Education, 19(1), 15-27. https://doi.org/10.1080/14675980701852228

Gudykunst, W., \& Nishida, T. (1986). Attributional Confidence in Low and High Context Cultures. Human Communication Research, 12, 525-549. https://doi.org/10.1111/j.1468-2958.1986.tb00090.x

Hedge, T. (2000). Teaching and Learning in the Language Classroom (6th ed.). Oxford: Oxford University Press.

Heo, H., Leppisaari, I., \& Lee, O. (2018). Exploring Learning Culture in Finnish and South Korean Classrooms. The Journal of Educational Research, 111(4), 459-472. https://doi.org/10.1080/00220671.2017.1297924

Hofstede, G. (2001). Culture's Consequences: Comparing Values, Behaviors, Institutions and Organizations Across Nations (2nd ed.). CA: Sage.

Hofstede, G., \& Hofstede, J. (2005). Culture and Organization Software of the Minds (2nd ed.). New York: McGraw-Hill.

Lee, G. (2009). Speaking Up: Six Korean Students' Oral Participation in Class Discussions in US Graduate Seminars. English for Specific Purposes, 28, 142-156. https://doi.org/10.1016/j.esp.2009.01.007

Lee, J., \& Kim, C. (2017). Teaching and Learning Science in Authoritative Classrooms: Teachers' Power and Students' Approval in Korean Elementary Classrooms. Research in Science Education, 49, 1367-1393. https://doi.org/10.1007/s11165-017-9659-6

Li, D. (1998). "It's Always More Difficult Than You Plan and Imagine": Teachers' Perceived Difficulties in Introducing the Communicative Approach in South Korea. TESOL Quarterly, 32(4), 677-703. https://doi.org/10.2307/3588000

Mitchell, R., \& Lee, J. (2003). Sameness and Difference in Classroom Learning Cultures: Interpretations of Communicative Pedagogy in the UK and Korea. Language Teaching Research, 7(1), 35-63. https://doi.org/10.1191/13621688031r114oa

Nguyen, P., Terlouw, C., \& Pilot, A. (2006). Culturally Appropriate Pedagogy: The Case of Group Learning in a Confucian Heritage Culture Context. Intercultural Education, 17(1), 1-19. https://doi.org/10.1080/14675980500502172

Osborn, M., Broadfoor, P., McNess, E., Planel, C., Raven, B., \& Triggs, P. (2003). A World of Difference? Berkshire UK: McGraw Hill.

Park, H., Lee, S., Yun, D., \& Kim, W. (2009). The Impact of Instructor Decision Authority and Verbal and Nonverbal Immediacy on Korean Student Satisfaction in the US and South Korea. Communication Education, 58(2), 189-212. https://doi.org/10.1080/03634520802450531

Shin, S., \& Koh, M. (2007). A Cross-Cultural Study of Teachers' Beliefs and Strategies on Classroom Behavior Management in Urban American and Korean School Systems. Education and Urban Society, 39(2), 286-309. https://doi.org/10.1177/0013124506295280

Simpson, S. (2008). Western EFL Teachers and East-West Classroom-Culture Conflicts. RELC Journal, 39(3), 381-394. https://doi.org/10.1177/0033688208096847

Tudor, D. (2012). Korea: The Impossible Country. Vermont: Tuttle Publishing.

Yan, H. (2020). Comparative Study of English Language Beliefs Between Chinese and Korean College Students in Minority Region. English Language Teaching, 13(2), 97-105. https://doi.org/10.5539/elt.v13n2p97 


\section{Appendix}

Questionnaire Questions

(Tests)

1. Without tests we cannot truly understand a student's ability.

\section{(Tests)}

2. A smart student should score well on tests.

\section{(Memorisation)}

3. Memorisation is the best way to get students to remember important information

(Responding to errors)

4. When a student makes a mistake, it is best to correct the mistake straight away.

(Responding to errors)

5. Sometimes I ignore errors completely as I feel it will disrupt the student's learning or confidence.

(Discipline)

6. Seating plans are important to create a good learning environment.

\section{(Discipline)}

7. Clearly explained classroom rules are important to ensuring class harmony.

(Group vs individual)

8. Class harmony is more important than individual happiness.

(Group vs individual)

9. When doing group work, having one student in a group who leads the group is helpful even if he / she dominates the group.

(Group vs individual)

10. Group work is important as it can make shier students feel included

(Student centred vs teacher centred)

11. I have a plan for my class and I feel uncomfortable if I do not follow that plan.

(Student centred vs teacher centred)

12. I will let my students have a say in what we study and how long we study it for.

(Student centred vs teacher centred)

13. I dislike it when I have made a mistake and a student corrects or questions me. 
(Student centred vs teacher centred)

14. I am the leader of my class.

(Student centred vs teacher centred)

15. It is my role as the teacher to give knowledge to my students.

(Student centred vs teacher centred)

16. Instructions should be explicitly stated rather than have students figure things out.

(Open ended)

17. Are there any differences in teaching / learning that you have noticed when observing foreign or Korean teachers when you compare Korean teaching to other countries?

\section{Interview Questions}

1. (Tests)

Are tests important to you as a teacher? How should we use tests with our students?

\section{2. (Memorisation)}

Do you use memorization techniques or methods in your classes? Do you think that memorization is an effective way to learn information.

3. (Individual vs Group)

Would you ever sacrifice individual student happiness or learning to maintain class happiness? If a student who learnt most effectively in a specific way, or enjoyed a specific activity, but the rest of the class didn't, would you choose the individual needs or the group needs? How and why might you make decisions about groups or individuals and where does your priority lie?

\section{4. (Lesson Plans)}

How important are lesson plans for you? Do you follow lessons exactly? How much detail might you go into for a lesson plan? Explain to me your approach to class structure.

\section{5. (Explicit Rules)}

Do you always have clearly explained class rules for your students, or do you let your students naturally learn class rules from watching others? Are class rules necessary for you? How might you use rules in your class?

\section{Copyrights}

Copyright for this article is retained by the author(s), with first publication rights granted to the journal.

This is an open-access article distributed under the terms and conditions of the Creative Commons Attribution license (http://creativecommons.org/licenses/by/4.0/). 